\title{
Determinants of management errors in acute severe asthma
}

\author{
John Kolbe, Marina Vamos, Wendy Fergusson, Gail Elkind
}

\begin{abstract}
Background - It is hypothesised that, despite recent initiatives to improve asthma self-management including asthma education, detailed investigation of the sequence of events culminating in hospital admission will lead to the identification of important management errors and thus the likelihood that the majority of severe asthma attacks are preventable by currently available strategies, and that psychological, health care and socioeconomic factors are risk factors for such management errors.

Methods - A cross sectional study was undertaken of 138 patients aged 15-50 years admitted to hospital (general ward or intensive care unit) with acute severe asthma who were assessed within 24-72 hours of admission using a number of previously validated instruments. A detailed history of events of the attack was assessed against predetermined criteria for non or delayed use of oral corticosteroids and non or delayed use of emergency ambulance services.
\end{abstract}

Results - Subjects had evidence of severe chronic asthma and had acute severe asthma at presentation $(\mathrm{n}=90, \mathrm{pH}=7.3$ $\left.(0.2), \mathrm{PaCO}_{2}=7.2(5.0) \mathrm{kPa}\right)$ but duration of hospital stay was short (3.7 (2.6) days). Serious management errors occurred very frequently and most were deemed to have been made by the patient. Forward stepwise regression revealed that delayed or non-use of oral corticosteroids was predicted independently by lack of paying job $(p=0.02)$, high total use of inhaled $\beta$ agonists in the $\mathbf{2 4}$ hours before index admission $(\mathbf{p}=0.04)$, loss of a job in the last year $(\mathbf{p}=$ $0.04)$, low frequency of use of oral corticosteroids in the last year $(p=0.06)$, concerns during the index attack about medical expenses $(p=0.07)$, and delay in the use of ambulance services $(p=0.05)$ - the model being responsible for $23 \%$ of the variance. Delayed or non-summoning of emergency ambulance services was predicted independently by total life events $(p=0.03)$, having something stolen in the last year $(p=0.003)$, panic during the index attack $(p=0.01)$, and concerns during the index attack about taking time off work $(p=0.07)$ - the model being responsible for $21 \%$ of the variance.

Conclusions - The results of this study show that, despite recent educational advances, serious management errors are common in those admitted to hospital with acute severe asthma and that most management errors relate to patient self-management behaviour. Serious management errors are predicted by a variety of socioeconomic and psychological factors. While the results of this study are consistent with the widely held view that most acute severe attacks are theoretically preventable, the challenge for the future is to change patients' behaviour in the face of considerable adverse socioeconomic and psychological factors.

(Thorax 1998;53:14-20)

Keywords: severe acute asthma, management errors, asthma education, psychological factors.

Most studies of deaths from asthma or severe life threatening attacks of asthma have identified a variety of management errors, either by the patient or the doctor, during the attack ${ }^{1-12}$ and, as a result, have frequently concluded that most such attacks are theoretically preventable by currently available strategies. ${ }^{125810-12}$ The British Thoracic Association study of asthma deaths estimated that potentially preventable factors contributed to $86 \%$ of the deaths. ${ }^{1}$ However, most of these studies have been retrospective ${ }^{12457-9}$ and did not use specific or previously defined criteria to determine whether a management error existed. ${ }^{1245910-12}$ In most cases this determination was made retrospectively by the authors and was often based on the gestalt impression of a panel, in turn dependent on retrospective information often obtained from grieving relatives. Such decision making was generally not "blinded" to the fact that death had occurred and was thus subject to considerable bias of various forms. Nevertheless, conclusions regarding the role and avoidability of management errors in acute asthma were the basis of major educational and other initiatives undertaken in New Zealand ${ }^{13}$ and which have been temporally associated with a marked decline in asthma morbidity and mortality. ${ }^{14}$ To what extent these factors remain operational following such interventions, and whether or not the considerable residual asthma morbidity and mortality is attributable to definable management errors and is thus preventable, is not clear.

We have previously shown that psychological, health care, and socioeconomic factors have powerful and differential influences on self-management knowledge and behaviour. Furthermore, the actual behaviour of patients during an acute severe attack was substantially inferior to their knowledge of the correct action 
to be undertaken in the circumstances. These discrepancies seemed greatest in terms of potentially life saving actions. ${ }^{15}$ It was to explore these issues further and to determine the factors associated with management errors that this study was undertaken.

Our hypotheses in relation to this study were (1) that detailed investigation of the sequence of events culminating in hospital admission will lead to the identification of important management errors and thus the likelihood that the majority of severe asthma attacks are preventable by currently available strategies, and (2) that psychological, health care, and socioeconomic factors are risk factors for such management errors.

\section{Methods}

STUDY DESIGN AND PATIENTS

A cross sectional study was undertaken of patients (aged 15-40 years) with acute severe asthma, normally resident in the Auckland region, admitted to the four major hospitals in the region. Patients aged $>50$ years were excluded to avoid the major inaccuracies in the diagnosis of asthma in older patients. The lower age limit is the age at which patients are transferred to adult clinics and are considered to be of sufficient maturity to assume responsibility for their own health. Patients were either admitted directly to the intensive care unit (ICU) with severe life threatening asthma (SLTA) ${ }^{16}$ or to the general medical wards. (A severe life threatening attack of asthma was defined as an attack requiring admission to the ICU plus at least one of the following: (i) cardiorespiratory arrest, (ii) requirement for mechanical ventilation, (iii) impaired conscious level at presentation, (iv) $\mathrm{pH}<7.2$, and (v) $\mathrm{PaCO}_{2}$ $\geq 6.0 \mathrm{kPa}$.) Patients were excluded if the primary reason for the admission was not acute asthma or if the patient was admitted primarily for a complication of asthma such as pneumothorax, pneumomediastinum, or because of the presence of other serious or life threatening illnesses. All patients satisfied the criteria for reversible airflow obstruction - that is, improvement of $>20 \%$ in peak expiratory flow (PEF) or forced expiratory volume in one second $\left(\mathrm{FEV}_{1}\right)$ with bronchodilator.

A detailed questionnaire was administered to all patients within 24-72 hours of admission to the general medical ward (either directly or after discharge from the ICU) by a single research associate. All components were administered by the interviewer and included: (1) patient demographic data; (2) quality of ongoing medical care and usual asthma management including acquisition of PEF meters, action plans, availability of oral steroids, accessibility of the family doctor ${ }^{17}$; (3) details of the patient's socioeconomic status with particular reference to aspects which may potentially influence asthma management including unemployment, financial dependence on social security benefits, financial difficulties in the last year, inability to afford doctor visits or prescription $\operatorname{costs}^{17}$; (4) asthma morbidity in terms of number of ICU ad- missions (ever and last 12 months), hospital admissions (ever and last 12 months), visits to emergency department in last 12 months, courses of oral corticosteroids in last 12 months and the need for continuous oral steroids ( $\geq 7.5 \mathrm{mg}$ prednisone/day for one month or more in the last 12 months); (5) level of anxiety and depression using the Hospital Anxiety and Depression (HAD) scale ${ }^{18}$ which is specific for distress in physically ill subjects. State-trait anxiety was also assessed on a Liekert-type scale. Denial of anxiety was defined by a high score on the HAD scale $(>10)$ in association with a patient's perception of low anxiety on the (state-) trait assessment - that is, as unawareness of anxiety in the presence of responses strongly suggestive of it; (6) social support measured by a modification of the scale of O'Reilly and Thomas ${ }^{19}$ which was originally designed to evaluate social support in patients with cardiac disease. This included an assessment of general support as well as disease specific support, both day to day and during acute attacks ${ }^{15}$; (7) life events using a validated modification for New Zealand of the life event scale of Tenant and Andrews ${ }^{20}$; (8) attitudes and beliefs about asthma using a modification of the instrument developed by Sibbald et $a .^{21}$ This questionnaire has also been extensively modified, consensual validity tested, ${ }^{22}$ and trialled in a patient group ${ }^{23}$; (9) patient behaviour during the index attack assessed by means of a very detailed history of symptoms and selfmanagement undertaken prior to admission to hospital. Particular attention was paid to selfmanagement strategies in relation to symptoms which defined "stages" in hypothetical scenarios. ${ }^{23}$ These scenarios have been developed to assess practical asthma self-management knowledge quantitatively. Briefly, one described an attack of increasing severity over seven days (slow onset) whilst the second described an attack which developed over one hour (rapid onset). Both scenarios end with the subject "experiencing" a severe attack such that he/she was so wheezy and short of breath as to be unable to speak or rise from a chair. Appropriate management strategies for managing such an attack were defined based on the Thoracic Society of Australia and New Zealand ${ }^{24}$ and British Thoracic Society ${ }^{25}$ consensus statements on the management of asthma.

The interviewer, who was unaware of the hypothesis being tested, determined the onset of the attack (defined as being more short of breath or wheezy than usual and/or increased use of inhaled bronchodilator) and classified the attack as rapid ( $<6$ hours) or slow $(\geq 6$ hours). Management errors were determined on the basis of pre-established criteria (Appendix 1). These in turn were based on the "stages" of the attack and the predetermined appropriate management strategies. It was therefore possible to determine whether a serious management error had occurred based on clear, predetermined criteria, the type of error, the stage in the attack at which it occurred, and who was responsible for it (Appendix 1). Subjects were also asked for their perception 
of difficulties encountered in managing this acute attack of asthma.

All subjects gave written informed consent to participate in the study which was approved by the Auckland Healthcare ethics committee.

\section{STATISTICAL ANALYSIS}

Data are expressed as mean (SD). Errors such as delay or non-use of oral corticosteroids and delay or non-summoning of emergency ambulance services were each treated as dependent variables. Univariate analyses were used to determine those independent variables (socioeconomic, health care, and psychological factors) that significantly predicted the error. General linear modelling was used to investigate multivariate relationships. Factors which were significant at $\mathrm{p}<0.05$ level were entered into the multivariate analysis to determine those variables which remained unique predictors of a significant amount of variance in the dependent variables even when all of the variance predicted by the other variables had been removed. Predictor variables $(p<0.1)$ from the multivariate analysis were then entered into a forward stepwise programme. A $\mathrm{p}$ value of $<0.05$ was regarded as statistically significant.

\section{Results}

One hundred and thirty eight subjects aged between 15 and 49 years (mean (SD) 30.3 (10.7) years) were recruited. One further patient refused to participate, one was excluded because of inadequate English language skills, and one was excluded for other reasons (severe mental retardation). Of the 138 subjects, $75 \%$ were female and $62 \%$ were European, $18 \%$ Maori, 18\% Pacific Island and 1\% other (this ethnic distribution being not significantly different from that of the Auckland population in this age bracket). English was the primary spoken language for $94 \%$ of patients.

Patients had acute severe asthma at the time of admission and substantial long term morbidity. Arterial blood gas data were available from the time of presentation or soon afterwards in 90 subjects $\left(\mathrm{pH}=7.3(0.2), \mathrm{PaCO}_{2}=\right.$ $7.1(5.0) \mathrm{kPa}$ ). Despite severe asthma on presentation, the duration of hospital stay was short (3.7 (2.6) days) with only $3.5 \%$ staying longer than seven days. Thirty five percent
Table 1 Perceived difficulties with management of index attack (subject responses)

\begin{tabular}{lc}
\hline Home alone & $15 \%$ \\
Lack of telephone & $1.4 \%$ \\
Lack of car & $8 \%$ \\
Unable to contact GP or urgent doctor & $1.4 \%$ \\
Unable to contact ambulance & $0.7 \%$ \\
Concern about cost of doctor & $16 \%$ \\
Lack of puffers/medicine & $15 \%$ \\
Lack of knowledge & $18 \%$ \\
Inappropriate advice & $3 \%$ \\
Panic & $28 \%$ \\
Concern about time off work & $20 \%$ \\
Other & $23 \%$ \\
\hline
\end{tabular}

had a previous ICU admission for severe life threatening asthma and $73 \%$ had a previous hospital admission (36\% in the last year). Patients had evidence of substantial chronic asthma symptoms with $59 \%$ indicating moderate or severe interference with exercise over the last year and $58 \%$ describing moderate or severe interference with sleep over the same period. Sixty three percent stated they used regular inhaled steroids $(34 \%<1000 \mu \mathrm{g} / \mathrm{day}$, $23 \% 1000-2000 \mu \mathrm{g} /$ day, and $17 \%>2000 \mu \mathrm{g} /$ day of beclomethasone dipropionate or equivalent in the two weeks prior to admission). Overall, $30 \%$ stated that their asthma control in the last year was better, $30 \%$ the same, and $41 \%$ worse than was usually the case.

Virtually all patients used inhaled $\beta$ agonists prior to admission, $68 \%$ using more than 10 puffs and $39 \%$ using more than 20 puffs in the 24 hours before admission. The difficulties in managing the index attack perceived by the patient are listed in table 1 (panic was a selfreported symptom and was perceived by the patient as interfering with their ability to manage the index attack). The serious management errors that occurred during the index attack (slow onset) and those responsible for them are shown in table 2. Factors independently associated with errors of delayed or non-use of oral corticosteroids in an acute attack and errors of delays or non-summoning of emergency ambulance services are shown in table 3. Using forward stepwise regression, lack of a paying job $(p=0.02)$, high total use of inhaled $\beta$ agonist in the 24 hours before index admission $(\mathrm{p}=0.04)$, loss of a job in the last year $(p=0.04)$, low frequency of use of oral corticosteroid in the last year $(p=0.06)$, concerns during the index attack about medical expenses $(p=0.07)$, and delay in use of emergency ambulance services $(p=0.05)$ were independently associated with

Table 2 Serious errors in management of index attack

\begin{tabular}{|c|c|c|c|c|c|c|}
\hline & \multicolumn{3}{|c|}{ Non-use of oral steroids } & \multicolumn{3}{|c|}{ Non-use of ambulance } \\
\hline & $1 a$ & $1 b$ & $1 c$ & $2 a$ & $2 b$ & $2 c$ \\
\hline Occurrence of error & $44 \%$ & $64 \%$ & $34 \%$ & $50 \%$ & $26 \%$ & $64 \%$ \\
\hline \multicolumn{7}{|l|}{ Error by: } \\
\hline Doctor & $7 \%$ & $9 \%$ & $8 \%$ & $0.8 \%$ & $23 \%$ & $1.5 \%$ \\
\hline Patient & $86 \%$ & $84 \%$ & $63 \%$ & $81 \%$ & $49 \%$ & $89 \%$ \\
\hline N/A & $8 \%$ & $7 \%$ & $29 \%$ & $18 \%$ & $49 \%$ & $9 \%$ \\
\hline
\end{tabular}

1 Non-use of oral steroids despite:

a marked interference with sleep or daily activities $>1$ day

b "very wheezy and breathless" with no response to repeated inhaled $\beta$ agonist;

c persistent and deteriorating symptoms.

2 Non-use of ambulance despite:

a patient so wheezy and breathless that difficult to speak or get up from a chair

b deterioration since beginning oral steroids;

c self-drive or driven by family member/friend to medical services despite fulfilling criteria 2 (a) or 2 (b). 
Table 3 Factors associated with serious management errors in slow onset attacks

\begin{tabular}{llll}
\hline & Partial $R^{2}$ & Model $R^{2}$ & $p$ value \\
\hline Delayed or non-use of oral corticosteroids & & & 0.02 \\
$\quad$ Lack of paying job & 0.057 & 0.057 & 0.04 \\
High total use of $\beta$ agonist in prior 24 hours & 0.042 & 0.099 & 0.04 \\
$\quad$ Loss of job in last year & 0.039 & 0.139 & 0.06 \\
$\quad$ Low frequency of oral corticosteroids in last year & 0.032 & 0.170 & 0.05 \\
Concern about medical expenses & 0.029 & 0.199 & 0.01 \\
$\quad$ Delay in use of ambulance services & & 0.061 & 0.003 \\
Delayed or non-use of emergency ambulance services & 0.061 & 0.143 & 0.03 \\
$\quad$ Panic during index attack & 0.082 & 0.182 & 0.07 \\
Having something stolen in last 12 months & 0.028 & 0.211 & \\
Total life events in last 12 months & & \\
Concern about taking time off work (during index attack) & & & \\
\hline
\end{tabular}

Factors not predictive included: educational and other demographic factors, attitudes and beliefs about asthma, ${ }^{152123}$ levels of anxiety and depression, level of self-management knowledge, ${ }^{23}$ previous asthma morbidity.

delayed or non-use of oral corticosteroids, the model being responsible for $23 \%$ of the variance. Panic during the index attack $(\mathrm{p}=0.01)$, total life events $(\mathrm{p}=0.03)$, having something stolen $(\mathrm{p}=0.003)$ in the last year, and concerns during the index attack about taking time off work $(p=0.07)$ were independently associated with delayed or non-summoning of emergency ambulance services, the model being responsible for $21 \%$ of the variance.

\section{Discussion}

The results of this study confirm that a substantial proportion of patients who experience acute attacks of asthma severe enough to require admission to hospital make clearly defined serious management errors during the acute attack. Previous studies have highlighted delays in instituting relevant therapy ${ }^{1-589127}$ so our criteria for management errors tended to be based on the time frame of instituting such therapy after reaching a certain stage of an attack rather than merely assessing whether such a strategy was used or not. Previous studies have highlighted the underuse of oral corticosteroids $^{1-5927}$ or the non-use of emergency ambulance services ${ }^{16}$ and these clearly remain a problem. This situation continues to exist despite the major educational and other initiatives introduced in New Zealand. ${ }^{1314}$ In addition, there were indicators of good quality ongoing asthma-specific medical care in this cohort $^{1517}$ which were consistent with the finding that most of the management errors were made by the patient rather than by the doctor. These findings, along with the disappointingly low standard of self-management behaviour in patients with moderate/severe asthma ${ }^{1523}$ and the marked discrepancies between knowledge and the actual behaviour during an attack, ${ }^{15}$ suggest that a major review of strategies for asthma self-management education is overdue. The concept of an average patient is a myth, and educational strategies should not be directed towards this mythical being.

Our results show that use of inhaled $\beta$ agonists during an acute attack remains excessive and is statistically associated with the delayed or non-use of oral corticosteroids. This situation persists despite various educational initiatives ${ }^{1314}$ and despite the fact that issues relating to the use of specific $\beta$ agonists (fenoterol) and $\beta$ agonists in general have received considerable publicity both in the lay and med- ical press in New Zealand. We have shown in a retrospective dynamic cohort study of persons attending a hospital emergency department for acute asthma that, after adjusting for differences in baseline risk, the risk ratio for asthma death or near fatal asthma for inhaled fenoterol compared with salbutamol fell from 2.1 to 1.0 , indicating that confounding by severity was entirely responsible for the increased crude risk ratio. ${ }^{27}$ However, one of the suggested mechanisms for this association between fatal and near-fatal asthma and asthma medications ${ }^{28}$ - specifically $\beta$ agonists ${ }^{272930}-$ is that over reliance on $\beta$ agonists during an acute attack is associated with delay in the use of potentially life saving oral corticosteroids. This contention is supported by the results of this study showing a strong association between overuse of inhaled $\beta$ agonists during an acute severe attack and delayed or non-use of oral corticosteroids (table 3). However, the precise mechanism of the association cannot be determined from a study of this type.

Difficulties perceived by the patients in management of the index attack were many and varied. The responses were a salutary lesson to the investigators in that many of the factors that we considered likely to be important or relevant turned out not to be the case and vice versa. Twenty three percent listed difficulties other than those we had defined; this translates into serious professional underawareness of potentially important details of action taken by patients during an acute attack and of the difficulties they encounter in management. However, these factors were many and varied suggesting the importance of individual patient circumstances and the fact that generic or nonspecific interventions are unlikely to be helpful. Further, there were marked discrepancies between what the patient volunteered as difficulties and those factors statistically associated with errors - specifically, indicators of socioeconomic disadvantage. This lack of concordance also has major implications for the development of intervention strategies to reduce asthma morbidity and mortality. On the one hand, issues perceived by the patient as being important need to be addressed by the clinician/asthma educator to maintain patient confidence and credibility while, on the other hand, other issues known to be associated with management errors need to be addressed.

The association between asthma morbidity $^{31-35}$ and mortality ${ }^{3536}$ and poverty is well 
recognised. This is generally considered to operate via greater exposure to aetiological and aggravating factors, or because of inadequate, poor quality or inaccessible health care, but socioeconomic disadvantage may also result from the direct or indirect effects of the illness. However, the adverse effects of socioeconomic disadvantage may be more subtle and insidious. We have previously shown that these factors impaired the ability to put into practice what had previously been learnt about asthma selfmanagement. ${ }^{15}$ In this study delayed or nonuse of oral steroids was independently associated with lack of a paying job, loss of a job, and concerns about medical costs during the index attack, all of which reflect adverse socioeconomic circumstances. The precise direction and mechanism of this association cannot be elucidated from this study, but the results are consistent with the hierarchical principle of behaviour changes in health education ${ }^{37}$ - that is, concerns about socioeconomic issues may so dominate and overwhelm the patient that they are unlikely to make correct self-management decisions or to benefit from educational interventions until these issues are addressed or at least acknowledged.

Low frequency use of courses of oral corticosteroids in the previous year was associated with errors in the use of oral corticosteroids. These results, along with previous results showing a positive association between admission to hospital and level of self-management knowledge and behaviour, ${ }^{15}$ may be summarised simply as "experience is the best teacher". While the association between self-management errors and concerns about taking time off work may merely reflect socioeconomic concerns, we have previously shown a high level of feeling of stigmatisation by the disease in patients with moderate/severe asthma. ${ }^{1523}$ Furthermore, McClellan and Garrett ${ }^{38}$ found that repeated hospital admissions and asthma-related sick leave from work were identified as "contributing factors to employment discrimination, job dismissal and lack of career advancement". In their study $77 \%$ of patients attending a hospital-based asthma clinic had not informed their employer of their asthma, $32 \%$ stated that there was a problem getting time off work to attend the clinic, and $8 \%$ considered that they had lost a job because of asthma. Such stigmatisation may lead to inappropriate self-management, particularly at work or in public.

Of interest is the fact that neither form of error was associated with the measured level of self-management knowledge. This merely serves to highlight our previous findings of the considerable gap which may exist between what a patient says they would do (knowledge) and what they actually do (behaviour) in the context of the development of an acute severe attack of asthma. ${ }^{15}$ It also argues that serious management errors such as those demonstrated in this study may not be avoided by conventional asthma self-management education specifically directed at improving knowledge.

Individual and total life events were associated with management errors. In order to make the appropriate self-management decisions the patient needs appropriate resources; these include social and financial resources as well as knowledge about the appropriate selfmanagement strategies. Life events are likely to combine and aggravate pre-existing vulnerability in terms of psychological, social, or economic burden to produce emotional distress. Such patients may have "no room left" to deal with the burden of managing day-to-day asthma and then to recognise and appropriately treat an acute exacerbation - that is, an emotional system and social organisation that is already overburdened by recent life events on top of other more chronic issues may not be able to detect the signals or appreciate the significance of them and act appropriately in an attack of asthma.

Psychological factors may affect the course of a chronic illness in a number of ways. Besides psychophysiological and psychoimmunological mechanisms, psychological stress may either heighten or lessen the awareness of symptoms or influence adherence or the desire or ability to work with health professionals. In this study most of the errors in management related to delays in instituting appropriate therapy. Jansen et $a l^{39}$ have shown a significant relationship between anxiety and depression (as measured by the Hospital Anxiety and Depression Scale) and the reporting of asthma-related symptoms such as waking with attacks of breathlessness. While the results of this study confirm our previous findings of a high rate of clinically significant anxiety in this patient group and a lower rate of depression in patients with severe asthma, ${ }^{1523}$ the delay in instituting oral corticosteroids and/or summoning emergency services was not related to anxiety or depression scores. This may be due to the difference between background anxiety - that is, the mood between attacks - and that present during the period when an attack is evolving and occurring. Also, our subjects represented a more severe patient group with higher levels of emotional distress and are thus more homogeneous than a community-based sample. However, high levels of panic/fear symptomatology during periods of asthma exacerbation function like signal anxiety, mobilising the individual to react and undertake appropriate self-management - that is, high symptom vigilance - although this is modified by levels of general/characterological anxiety. ${ }^{40}$ As such, the notion (because of the high levels of measured anxiety in asthma) that the key to a behavioural approach to the management of asthma is a reduction in anxiety is simplistic, unlikely to produce desirable results, and may be counterproductive if the adaptive symptom vigilance is not left intact. Nevertheless, some patients perceived that panic interfered with their ability to manage the index attack and indeed this was statistically associated with errors in summoning emergency ambulance services.

Rather than merely presenting those individual factors statistically associated with management errors, we have attempted to define that set of factors which - independent of each other - best describe the likelihood of 
management error. One possible concern about the clinical usefulness of the results of this study is that the models developed explain only just over $20 \%$ of the occurrence. This could mean that, in most patients, other factors as yet unidentified may have a major influence on the likelihood of serious management errors. This is considered unlikely. It is more likely that different factors may be operable in different patients, possibly at different times, and thus not achieve statistical significance in a study of this type. Thus it is not possible to produce a robust set of predictions for the likelihood of management errors. Rather, the factors identified in this study need to be explored and addressed in all patients with moderate/severe asthma.

On theoretical grounds, and because most of the management errors are defined in terms of substantial delays or non-performance of an action, the management errors defined in this study are preventable by currently available strategies. However, it is necessary to reflect on whether this is really the case - that is, the difference between the theoretical and the practical. To eliminate such management errors requires changes in patient behaviour. However, this group of patients has a high frequency of adverse psychological factors, especially anxiety and major socioeconomic disadvantage, ${ }^{17}$ and we have previously shown that not only do such factors have a powerful and differential influence on the acquisition of knowledge, but also on the translation of that knowledge into asthma-related behaviour ${ }^{15}$ and, in this study, on the likelihood of making serious management errors. To prevent these errors occurring, these powerful social, economic, and psychological influences also therefore have to be comprehensively addressed and this is the challenge for asthma educational interventions in the future.

\section{Appendix 1}

SLOW ONSET OF ATTACK (SERIOUS ERRORS)

(1) Delayed seeking medical help or starting course of oral steroids was defined as action not undertaken in the following circumstances:

(a) interference with daily activities over more than one day and interference with sleep over the previous one or more nights;

(b) feeling "very wheezy and breathless" without significant response to inhaled $\beta$ agonists over one hour;

(c) persistent and deteriorating symptoms over a period of three or more days.

(If help sought from doctor and steroids not instituted under these circumstances it is regarded as an error of management on the part of the GP.)

(2) Inadequate or delayed use of emergency services was defined as action not taken under the following circumstances:

(a) so wheezy and breathless they find it difficult to speak or get up from a chair (within 30 minutes);

(b) failure to present to emergency medical services if continues to deteriorate in the four or more hours following oral corticosteroids;

(c) self-drive or driven by member of family to medical services under circumstances described in (a) or (b).

RAPID ONSET OF ATTACK (SERIOUS ERRORS) (1) Delayed seeking medical help or starting course of oral corticosteroids was defined as action not taken within 30 minutes in the following circumstances: (a) rapidly worsening wheeze and breathlessness unresponsive to inhaled $\beta$ agonist;

(b) rapidly worsening wheeze and breathlessness such that unable to walk from room to room.

(2) Inadequate or delayed use of emergency services was defined as action not taken under the following circumstances:

(a) so wheezy or breathless they find it difficult to speak or get up from a chair (within 15 minutes);

(b) continued rapid deterioration after starting course of oral steroids (over 30-60 minutes);

(c) self-drive or driven by member of family to medical services (under similar conditions).

This study was supported by grants from Lottery Health Research, New Zealand and Health Research Council of New Zealand. The authors thank Miss Margaret McKinlay for her assistance in the preparation of the manuscript.

1 British Thoracic Association. Deaths from asthma in two regions of England. BMF 1982;285:1251-5.

2 MacDonald JB, Seaton A, Williams DA. Asthma deaths in Cardiff 1963-74: 90 deaths outside hospital. BMF 1976; 1:1493-5.

3 Westerman DE, Benatar SR, Potgieter PD, Ferguson AD Identification of the high-risk asthmatic patient. Experience with 39 patients undergoing ventilation for status perience with 39 patients undergoing ven

4 Ormerod LP, Stableforth DE. Asthma mortality in Birmingham 1975-7: 53 deaths. BMF 1980;1:687-90.

5 Sears MR, Rea HH, Beaglehole R, et al. Asthma mortality in New Zealand: a two year national study. NZ Med $\mathscr{f}$ 1985;98:271-5

6 Rea HH, Scragg R, Beaglehole R, et al. Asthma mortality in New Zealand: a case-control study. Thorax 1986;41 $833-9$

7 Miller BD, Strunk RC. Circumstances surrounding the deaths of children due to asthma. Am F Dis Child 1989; 143:1294-9.

8 Miller TP, Greenberger PA, Patterson R. The diagnosis of potentially fatal asthma in hospitalised adults. Patients characteristics and increased severity of asthma. Chest 1992;102:515-8.

9 Kollenbach JM, Frankel AH, Lapinsky SE, et al. Determinants of near fatality in acute severe asthma. $A m \mathcal{F}$ Med 1993;95:265-72.

10 Wareham NJ, Harrison BDW, Jenkins PF, Nicholls J, Stableforth DE. A district confidential enquiry into deaths due to asthma. Thorax 1993;48:1117-20.

11 Birkenhead G, Attaway NJ, Strunk RD, Townsend MC, Teutsch S. Investigation of a cluster of deaths of adolescents from asthma: evidence implicating inadequate treatment and poor patient adherence with medications. f Allergy Clin Immunol 1989;84:484-91.

12 Rea HH, Sears MR, Beaglehole R, et al. Lessons from the national asthma mortality study: circumstances surrounding death. NZ Med fै 1987;100:10-13.

13 Kolbe J, Garrett J, Vamos M, Rea H. Influences on trends in asthma morbidity and mortality: the New Zealand experience. Chest 1994;104(Suppl 4):S211-5.

14 Garrett J, Kolbe J, Richards G, Whitlock RML, Rea H. Major reduction in asthma morbidity and continued reduction in asthma mortality in New Zealand: what lessons have been learned? Thorax 1995;50:303-11.

15 Kolbe J, Vamos M, Fergusson W, Elkind G, Garrett J. Differential influences on asthma self-management knowledge and self-management behaviour in acute severe asthma. Chest 1996;110:1463-8.

16 Richards GN, Kolbe J, Fenwick J, Rea HH. Demographic characteristics of severe life-threatening asthma: comcharacteristics of severe life-threatening asthma: con
parison with asthma deaths. Thorax $1993 ; 46: 105-9$.

17 Kolbe J, Vamos M, Fergusson W, Elkind G, Garrett J Socio-economic disadvantage, quality of medical care and admission for acute severe asthma. Aust NZ F Med 1997; 27: 294-300.

18 Zigmond AS, Snaith RP. The hospital anxiety and depression scale. Acta Psychiatr Scand 1983;67:361-70.

19 O'Reilly P, Thomas HE. Role of support networks in maintenance of improved cardiovascular health status. Soc Sci Med 1989;28:249-60.

20 Tenant C, Andrews G. A scale to measure the stress of life events. Aust NZ F Psychiatry 1976;10:27-32.

21 Sibbald B, Collin J, De Soyza M. Questionnaire assessment of patients' attitudes and beliefs about asthma. Family Practice 1986;3:37-41.

22 Vamos M, James F, Kolbe J. Cultural issues facing medica research in New Zealand. Short report on asthma pilot study. NZ Med f 1994;107:132-3.

23 Kolbe J, Vamos M, James F, Elkind G, Garrett J. Assessment of practical knowledge of self-management of acute asthma. Chest 1996;109:86-90.

24 Woolcock A Rubinfeld AR, Seale JP, et al. Asthma management plan. Med f Aust 1989;151:650-3.

25 Brewis G. Guidelines for the management of asthma in adults. 1. Chronic asthma. BMF 1990;301:651-3.

26 Brewis G. Guidelines for the management of asthma in adults II. Acute severe asthma. BMF 1990;301:797-80.

27 Garrett J, Lane S, Kolbe J, Rea H. Risk of severe lifethreatening asthma and the type of prescribed $\beta$ agonist: 
an example of confounding of severity. Thorax 1996;51: 1093-9.

Garrett JE, Lanes SF, Birmann BM, Kolbe J. The association between asthma drugs and severe lifethreatening asthma. Chest 1996;110:1446-51.

29 Spitzer WO, Suissa S, Ernst P, et al. The use of $\beta$ agonists and the risk of death and near death from asthma. N Engl f Med 1992;326:501-6.

30 Suissa S, Ernst P, Boivin JF, et al. A cohort analysis of excess mortality in asthma and the use of $\beta$ agonists. Am F Respir Care Med 1994;149:604-10.

31 Peckham C, Bulter NA. A national study of asthma in childhood. $\mathcal{f}$ Epidemiol Community Health 1978;32: 79-85.

32 Mitchell RG, Dawson B. Educational and social characteristics of children with asthma. Arch Dis Child 1993; 48:167-71.

33 Littlejohns P, MacDonald CD. The relationship between severe asthma and social class. Respir Med 1993;87:13943.
34 Wissor LS, Gittelsohn AM, Szklo M, Starfield B, Mussman $M$. Poverty, race and hospitalisation of childhood asthma. Am $\mathcal{F}$ Public Health 1988;78:777-92.

35 Carr W, Zeittel L, Weiss K. Variations in asthma hospitalisations and deaths in New York City. Am f Public Health 1992;82:59-65.

36 Jackson GP. Asthma mortality by neighbourhood of domicile. NZ Med f 1988;101:593-5.

37 Green LW, Frankish CJ. Theories and principles of health education applied to asthma. Chest 1994;106(Suppl):219 $30 \mathrm{~S}$

38 McClellan V, Garrett J. Attendance failure at Middlemore Hospital asthma clinic. NZ Med f 1989;102:211-3.

39 Jenson C, Bjornsson E, Hetta J, Boman G. Anxiety and depression in relation to respiratory symptoms and asthma. Am $\mathcal{F}$ Respir Crit Care Med 1994;149:430-4.

40 Dirks JF, Kinsman RA, Staudenmeyer H, Kleiger JH. Panicfear in asthma. Symptomatology as an index of signal anxiety and personality as an index of ego resources. $\mathcal{F}$ Nervous Mental Dis 1979;167:615-9. 


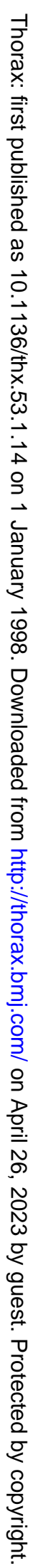

